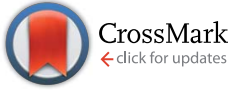

Cite this: RSC Adv., 2016, 6, 74085

DOI: $10.1039 / c 6 r a 90064 j$

www.rsc.org/advances

\section{Correction: Polyacrylonitrile/Syzygium aromaticum hierarchical hydrophilic nanocomposite as a carrier for antibacterial drug delivery systems}

\author{
Ramdayal Yadav and K. Balasubramanian*
}

Correction for 'Polyacrylonitrile/Syzygium aromaticum hierarchical hydrophilic nanocomposite as a carrier for antibacterial drug delivery systems' by Ramdayal Yadav et al., RSC Adv., 2015, 5, 3291-3298.

The authors regret their oversight in publishing an incorrect version of Fig. 1 and the corrected version is shown below:

In this context, the abstract of the manuscript should be modified as follows.

A versatile maneuverable electrospinning process was exploited to fabricate intertwined heterostructure polyacrylonitrile (PAN) nanofibers with average diameter of $141.0 \mathrm{~nm}$ by incorporating essential oil Syzygium aromaticum for antibacterial drug delivery systems. We have demonstrated the formation of seamless heterostructure of PAN/Syzygium aromaticum nanocomposites by incorporating $0.1 \%$ electrolyte solution, which not only achieved an inhibition zone of $1.8-2.8 \mathrm{~cm}$ against Gram positive and Gram negative bacteria but also exhibited $100 \%$ cell viability of NIH/3T3 cell lines. Electrospun fibers were observed to be flexible and composed of continuous, cylindrical and randomly oriented fibers. an FT-IR peak at $3398 \mathrm{~cm}^{-1}$ reveals the ultra-wettabililty nature of the nano-composite which was confirmed by contact angle measurement. Further, the Krosmeyar-Peppas model was explored to study the mechanism and kinetics of the antibacterial drug release system. The overall result suggests that electrospinning can be employed as a novel, facile route for the large scale fabrication of nanoscale PAN heterostructure hydrophilic composites for a broad range of biomedical applications. 

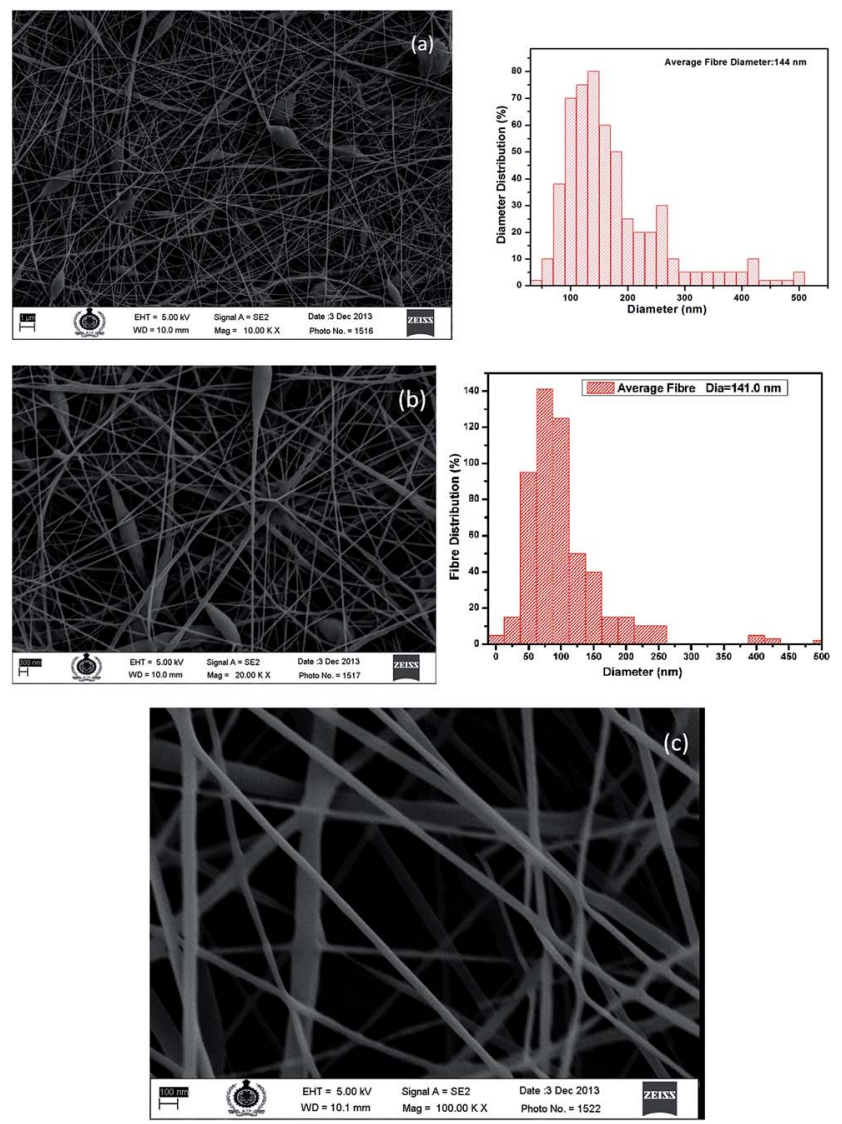

Fig. 1 SEM images of electrospun nanofibers of (a) PAN/Syzygium aromaticum oil nanofibers and (b) PAN/Syzygium aromaticum oil nanofibers with $0.1 \%$ electrolyte at $10 \mathrm{k} \times$ magnification; (c) $100 \mathrm{k} \times$ magnified fibers.

The Royal Society of Chemistry apologises for these errors and any consequent inconvenience to authors and readers. 